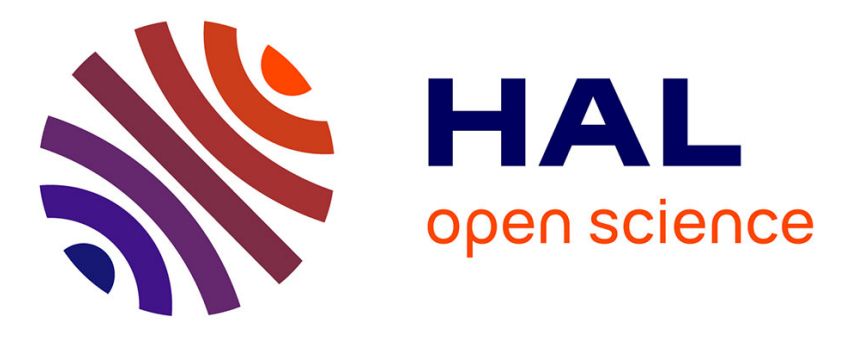

\title{
Estimation of the frequency of involuntary infertility on a nation-wide basis
}

\author{
Rémy Slama, Oluf Kristian Højbjerg Hansen, Béatrice Ducot, Aline Bohet, \\ Ditte Nørbo Sorensen, Lise Giorgis Allemand, Marinus J. C. Eijkemans, \\ Lyliane Rosetta, Jean-Christophe Thalabard, Niels Keiding, et al.
}

\section{To cite this version:}

Rémy Slama, Oluf Kristian Højbjerg Hansen, Béatrice Ducot, Aline Bohet, Ditte Nørbo Sorensen, et al.. Estimation of the frequency of involuntary infertility on a nation-wide basis: A nation-wide survey of couple fecundity. Human Reproduction, 2012, epub ahead of print. 10.1093/humrep/des070 . inserm-00680532

\section{HAL Id: inserm-00680532 https://www.hal.inserm.fr/inserm-00680532}

Submitted on 19 Mar 2013

HAL is a multi-disciplinary open access archive for the deposit and dissemination of scientific research documents, whether they are published or not. The documents may come from teaching and research institutions in France or abroad, or from public or private research centers.
L'archive ouverte pluridisciplinaire HAL, est destinée au dépôt et à la diffusion de documents scientifiques de niveau recherche, publiés ou non, émanant des établissements d'enseignement et de recherche français ou étrangers, des laboratoires publics ou privés. 


\section{Estimation of the frequency of involuntary infertility on a nation-}

\section{2 wide basis}

3

4 Running title:

5 A nation-wide survey of couple fecundity

6

7 Authors:

8 R. Slama ${ }^{1,2}$, O. Hansen ${ }^{3}$, B. Ducot ${ }^{4,5}$, A. Bohet ${ }^{4,5}$, D. Sorensen ${ }^{3}$, L. Giorgis Allemand ${ }^{1,2}$,

9 M.J.C. Eijkemans ${ }^{6}$, L. Rosetta ${ }^{7}$, J.C. Thalabard ${ }^{8}$, N. Keiding ${ }^{3}$, J. Bouyer ${ }^{4,5}$

1: Inserm, Institut Albert Bonniot (U823), Team of Environmental Epidemiology applied to Reproduction and Respiratory Health, F-38042 Grenoble, France.

2: Grenoble University, Institut Albert Bonniot, Grenoble, France.

3: Department of Biostatistics, University of Copenhagen, Denmark.

4: Inserm, CESP, Centre for research in Epidemiology and Population Health, U1018, Reproduction and child development Team, F-94276 Le Kremlin-Bicêtre, France

5: Univ Paris-Sud, UMRS 1018, F-94276, Villejuif, France

6: Julius Center for Health Sciences and Primary care, UMC Utrecht, The Netherlands.

7: CNRS, UPR 2147, Paris.

8: MAP5, UMR CNRS 8145, Paris Descartes University, Paris.

Corresponding author:

Rémy Slama, remy.slama@ujf-grenoble.fr

Word count:

Abstract: 246 
1

2

3

4

5

6

7

8

9

10

11

12

\section{ABSTRACT}

BACKGROUND: Assessing the couple fecundity on a nation-wide basis without excluding couples who eventually remain infertile is challenging. Our aim was to describe the couple fecundity (in terms of frequency of involuntary infertility) among the general population living in France. METHODS: We used a current-duration design. A random sample of 64,262 households was selected in 2007-2008, allowing us to identify 15,810 women aged 18-44 years. Eligible women $(n=1089)$ were those having regular sexual intercourse with a male partner, not using any method of contraception and not having delivered in the previous 3 months. These women reported information on the current duration of unprotected intercourse (CDUI, the time elapsed between the start of the period of unprotected intercourse and the time of inclusion in the study). The CDUI distribution was used to estimate the frequency of involuntary infertility, using a newly developed statistical technique that does not require couples to be followed-up until the end of the period of unprotected intercourse. RESULTS: CDUI was defined for 867 women. An estimated $46 \%$ of couples had no detected pregnancy conceived during the first 6 months of unprotected intercourse $(95 \%$ confidence interval, 36-56\%). The proportions of couples with no detected pregnancy within 12 and 24 months were 24\% (19-30\%) and 11\% (8-14\%), respectively. CONCLUSIONS:

These results constitute one of the few descriptions of the fecundity of a nation-wide representative sample of couples from the general population, not limited to couples who eventually conceived or to those resorting to medical help.

Key words: Fecundability; Fecundity; Infertility; Involuntary infertility; Pregnancy; 
1

2 Few descriptions of the couples' ability to conceive a pregnancy (fecundity) exist in non3

\section{INTRODUCTION}

selected groups of the general population. Fertility, the actual number of children per woman,

is monitored in most countries and is statistically associated with having a time to pregnancy

longer than 12 months (Joffe, et al., 2009). However, outside the specific context of populations not using contraceptive methods (Larsen and Vaupel, 1993), it constitutes a very indirect and probably not very sensitive indicator of the occurrence of impaired fecundity.

Data on the use of assisted reproduction technologies (ART) are widely available (de Mouzon, et al., 2010, de Mouzon, et al., 2009), but information on the number of couples resorting to ART is difficult to interpret without knowledge of the population at risk (those trying to become pregnant), and because involuntarily infertile couples seek for medical help after variable durations of unprotected intercourse (Moreau, et al., 2010) and do not always resort to ART.

Fecundity studies relying on a pregnancy-based design have been conducted in several countries (Jensen, et al., 2001, Juul, et al., 1999, Muller, et al., 2006) (reviewed by Leridon, 2007), but this design excludes couples who do not conceive finally, thus overestimating the fecundity level. Few surveys including couples who remain infertile have been conducted. The European Studies of Infertility and Subfecundity (Karmaus, et al., 1999), a set of retrospective studies conducted in Denmark, Germany, Poland, Italy and Spain in 1991-93, considered unsuccessful attempts at pregnancy. Some cohort studies of pregnancy planners have been conducted, but generally for etiologic or biologic purposes rather than to describe fecundity at the population level, and in selected populations (Bonde, et al., 1998, Buck, et al., 2004, reviewed by Guzick and Swan, 2006, Tietze, 1968, Weinberg, et al., 1994, Wilcox, et al., 1988, Zinaman, et al., 2000). Demographers have also studied perceived fecundity or impaired fecundity in the general population, for example in France (Leridon, 1992, Leridon, 2007) or in the US National Survey of Family Growth (Stephen and Chandra, 2006); these studies, usually relying on large and well-defined population based samples are difficult to compare to the above-mentioned "time to pregnancy" studies, either because they did not 
1 use an objective cut-off (e.g., 12 or 24 months) to define involuntary infertility (Leridon, 1992)

2 or, in the case of the National Survey of Family Growth, because the number of cases of 3 (current) 12-month infertility is not divided by the number of couples (currently) at risk of 4 pregnancy, but by the size of the (larger) group of married women, regardless of whether

5 they were "at risk" of pregnancy, leading to a much lower rate of involuntary infertility than in 6 other studies (Guzick and Swan, 2006).

7 Our aim was to describe the frequency of involuntary infertility among the general population of France without excluding couples involuntarily infertile. In terms of approach and study design, the need to efficiently include infertile couples (Olsen and Rachootin, 2003, Sallmen, et al., 2000, Slama, et al., 2004) implied the exclusion of retrospective designs. Among prospective designs, the main options are the incident cohort design (Bonde, et al., 1998), the prevalent cohort design (Keiding, 1992, Wise, et al., 2010), and the current duration approach (Keiding, et al., 2002, Slama, et al., 2006). The very low eligibility rate of the incident cohort design -probably around 1\% of women of reproductive age (Bonde, et al., 1998, Slama, et al., 2006) - made it in our eyes little suited for descriptive studies. The first stage of the prevalent cohort design requires one to recruit a cross-sectional sample of couples not using contraception and to collect the time elapsed since the start of the period at risk of pregnancy to account for left-censoring in the analysis; this first stage also corresponds to a current duration approach, which is therefore embedded into the prevalent cohort design. We have recently demonstrated the feasibility of this design (Slama, et al., 2006). For these reasons, we chose to use a current duration approach (Keiding, et al., 2002, Slama, et al., 2006, Weinberg and Gladen, 1986). 
1

2 The study, termed the Observatory of Fecundity in France (Obseff), aims is to describe the

3 fecundity of couples from the general population at the nation-wide level, to describe

4 characteristics of menstrual cycle function using urinary biomarkers and to characterize the

5 influence of environmental factors (in particular atmospheric pollutants) on fecundity; only the

6 first aim is presented here. Our study follows the methodology of our feasibility study on the

7 current duration approach (Slama, et al., 2006), with slight modifications.

8

9 Population sample

Our approach was a two-stage stratified sampling (Slama, et al., 2006). At the first stage, a random probability sample of households was selected using a stratified random sample of all landline phones in mainland France ( $86 \%$ of households had a landline phone at the time of the survey). Subjects who only had a mobile phone or no phone were not included in the sample. Households in areas corresponding to urban areas of more than 100,000 inhabitants were over-sampled and corresponded to about $61 \%$ of the random list of phone numbers (compared to $46 \%$ in the whole French population), a feature taken into account in the analysis by a reweighing approach (see below).

\section{Eligibility criteria}

Eligible households were those which were the main residence of a woman aged 18 to 44 years; if several women in this age range lived in the selected household, we randomly drew one, without selecting another one if she turned out not to be eligible. Women aged 18 to 44 years (i.e. between their $18^{\text {th }}$ and $45^{\text {th }}$ birthdays) answered an eligibility questionnaire lasting about 4 minutes. Eligible women were those living with a male partner or engaged in a regular relationship with a male partner, who were not regularly using any method to avoid pregnancy (nor was their partner) at the time of the study. The interviewer asked questions about all types of methods to avoid pregnancy, enumerating all of them. Couples sporadically using contraception were not considered to be eligible, unless they simultaneously declared that they were trying to become pregnant. Women who did not have sexual intercourse in the 
1 month prior to interview, and women who had delivered in the 3 months prior to interview

2 were excluded. Women were asked if they were currently trying to become pregnant, but this

3 was not an eligibility criterion. Indeed, following the logic of a previous study (Karmaus, et al.,

4 1999), our aim was to capture the whole population theoretically at risk of pregnancy,

5 whatever their fecundity level, without excluding those who are subfertile or may consider

6 themselves sterile after some duration of involuntary infertility. For the same reason, we did

7 not exclude from the main analysis women with irregular menstrual periods or couples in

8 which a male fertility disorder (e.g., low sperm count) had been diagnosed. Sensitivity

9 analyses excluding "non-planners" (defined with respect to the start of the period of

10 unprotected intercourse) and women without menstrual bleeding in the last 12 months are

11 provided (see below).

\section{Correction for population sampling and selection bias}

We used a weighting approach to correct for possible differences between the women who accepted to reply to the eligibility questionnaire and women from the general population, and to correct for the over-sampling of subjects living in urban areas of more than 100,000 inhabitants. First, a weight correcting for the over-sampling of large urban areas was defined; a weight correcting for the lower probability of inclusion of women who were not the only woman aged 18 to 44 years in the home was then generated. Finally a weight allowing the recruited population of women aged 18 to 44 years who answered the eligibility criteria to be more similar to the general population of women in this age range (based on the distributions of age, marital life, number of children, age at the end of studies observed in the national census) was created. The estimation of this last weight was based on a generalized raking procedure (Deville, et al., 1993) and was implemented using CALMAR macro implemented on SAS statistical software (INSEE). Finally, these weights were multiplied, and the corresponding final weight was used in all analyses.

Current duration of unprotected intercourse 
1 The main outcome was the rates of 6-month (respectively 12- and 24-month) involuntary 2 infertility, defined as the proportion of couples without a recognized pregnancy within 6 3 months (respectively, 12 or 24 months) of unprotected intercourse (although the term 4 involuntary tends to assume that couples wished to become pregnant -at least at the start of 5 the period of unprotected intercourse- we also used it in analyses including all periods of 6 unprotected intercourse, even those started in the absence of a pregnancy wish). These 7 outcomes were derived from the current duration of unprotected intercourse (CDUI), using an approach outlined below. CDUI corresponds to the time elapsed between the start of the period of unprotected intercourse and the interview. Women were also asked to provide the duration elapsed since they last used a method to avoid pregnancy (in weeks, months and years), if any, which was used if the date was missing. The starting date of the period of unprotected intercourse was determined in three different ways. For the majority of women $(63 \%)$, it corresponded to the date of discontinuation of use of the last contraceptive method, as declared by the woman. Women were asked if, upon discontinuing use of contraception, they had waited for 1,2 or 3 cycles before actively trying to become pregnant; if this was the case then 28,56 or 84 days, respectively, were subtracted from CDUI. We also checked that no pregnancy declared by the woman had occurred since this date, and corrected the starting date accordingly if this was not the case. If the couple had not used any method to avoid pregnancy since the last pregnancy (32\% of women), then the starting date was defined as the end of the last pregnancy, plus three months in case of a live or stillbirth; if the resulting assumed starting date was after the date of interview (e.g., for women who delivered a live newborn in the previous 3 months), then the couple was not considered to be eligible. For couples who had never used any method to avoid pregnancy and in which the woman had never been pregnant ( $5 \%$ of women), the starting date was that of the start of the relationship.

Estimation of the probability of pregnancy 
1 The principle of the current duration approach is to infer the underlying distribution (or

2 survival function) corresponding to an unobserved time interval until a given event, from the

3 distribution of the so far elapsed part of this time interval (Keiding, et al., 2002, van Es, et al.,

4 2000, Weinberg and Gladen, 1986, Yamaguchi, 2003). Here, we are interested in total time

5 interval of unprotected intercourse before a pregnancy (if any), but we only observe couples

6 not using contraception at a certain time period (the time of interview), without following them

7 up like in a cohort study. More precisely, the end of the period of unprotected intercourse, in

8 addition to successful conception, may also happen because the couple gives up (resumes

9 contraception because the couple considers it is not anymore a good time to become pregnant, e.g. as a result of a change in their financial situation, or because the couple splits, becomes too old, die). The possible onset of fertility treatment can also be considered as the end of the period of unprotected intercourse, but another interpretation is possible. Indeed, it is possible to argue either that fertility treatments change to some extent the probability of conception away from the primary interest, so that the relevant time is unprotected intercourse before onset of medical infertility treatment; in other words, we then consider start of fertility treatment as another way of giving up trying. Alternatively, one may consider that the couple is still trying to become pregnant during fertility treatment, if our focus is the actual fecundity in today's society as it is (in which case onset of such treatments can be ignored in analyses). We present both results here since each one has its logic. Note that this way of handling a competing risk is necessary in the current duration approach in order to avoid complex hypotheses on the transition rate to infertility treatments, and that it differs from classical prospective (e.g., Cox) survival modelling, in which fertility treatments can be handled by censoring or as competing risks. Infertility treatments were assessed by asking specifically if each type of medical infertility treatment (drugs, artificial insemination, in vitro fertilization, intra-cytoplasmic sperm injection) had been used by the woman or her partner, and when.

The survival function corresponding to this underlying distribution has been estimated using a parametric approach assuming a generalized gamma distribution (Keiding, et al., 2002, 
1 Yamaguchi, 2003). Confidence intervals were built using a bootstrap approach. The

2 estimations were repeated restricting the population to women declaring that they were

3 currently trying to become pregnant or that they had stopped using a contraceptive method

4 because they wished to become pregnant (thereafter called "pregnancy planners"). A

5 modification of the approach initially proposed (Keiding, et al., 2002, Slama, et al., 2006)

6 regards very long current durations of unprotected intercourse. Many of these long durations

7 most probably concern couples who are aware of strong subfertility or even sterility, and

8 since our interest is in the shape of the distribution of time to pregnancy for the very first

9 years, we based the estimation on all durations shorter than 36 months and replaced

10 (without excluding them) those reported as being longer than 36 months by the information

11 that they were longer than 36 months.

The resulting estimated survival function can be interpreted as an estimate of the proportion of couples who, after a given number of months, still have unprotected intercourse (that is, they did not give up the period of unprotected intercourse) and did not obtain a clinically detected pregnancy. In the case where couples with infertility treatments are excluded, it is an estimate of an alternative fecundity measure, namely the proportion of couples who, after a given number of months, still have unprotected intercourse and have neither obtained a clinically detected pregnancy nor started fertility treatment.

Sensitivity analyses

We repeated the estimation of the proportion of couples who still have unprotected intercourse in various subgroups or imposing alternative sets of assumptions: 1) assuming that couples who had not resumed contraception since their last pregnancy had a duration of post-partum infertility of 6 months (instead of 3 in the main analysis); 2) excluding women who declared not to have had menstrual cycles in the last 12 months; 3) excluding couples who declared that they had used contraception sporadically (included in the main analysis if they declared to be currently trying to become pregnant) and 4) including couples with sporadic contraception mentioned in 3) above, but assigning them a reduced CDUI, to 
1 account for the fact that they were not exposed to pregnancy risk during all months since the

2 start of the pregnancy attempt; in practice, we arbitrarily halved their CDUI. 
1

2 Population sample

3 We drew a random sample of 64,262 households, 19,121 of which were the main residence

\section{RESULTS} of an 18-44 year old woman; 15,810 of these women accepted to reply to the eligibility questionnaire (Figure I). Among women aged 18-44 years, $4.8 \%$ were pregnant at the time of the eligibility questionnaire; $5.5 \%$ reported that they were currently trying to become pregnant and $4.4 \%$ declared that they planned to try to become pregnant within the next 12 months (Table I). Half of the women (48\%) reported that they had no intention to try to become pregnant in the future.

\section{Estimation of the frequency of infertility}

Among the women who answered the eligibility questionnaire, $1089(6.9 \%)$ were eligible; that is, they were not using any birth control method, had a male partner and had been sexually active in the previous month. Out of these, 943 accepted to participate. The estimated overall participation rate was $63 \%$ (Figure I). The current duration of unprotected intercourse (CDUI) could be defined for 867 participating women. The characteristics of women with a defined CDUI are shown in Table II. The median duration of CDUI, which has no direct interpretation, was 13.2 months, with $25-75^{\text {th }}$ percentiles equal to $3.7-41.8$ months. From CDUI, we estimated the underlying "survival" function, corresponding to the time to conception or end of the period of unprotected intercourse for the source population (Figure IIA). The estimated proportion of couples who would still not have conceived and would still be having unprotected intercourse 6 months after the start of the interval of unprotected intercourse was $46 \%$ (95\% confidence interval, $\mathrm{Cl}, 36-56 \%)$; it was $24 \%(95 \% \mathrm{Cl}, 19-30 \%)$ and $11 \%$ (95\% Cl, 8-14\%) within 12 and 24 months after the start of the period of unprotected intercourse, respectively. Values were very slightly lower after restriction to the 708 couples who declared that they had stopped using birth control methods in order to obtain a pregnancy: rates were $45 \%(95 \% \mathrm{Cl}, 34-55 \%), 23 \%(18-28 \%)$ and $10 \%(8-12 \%)$ at 6,12 and 24 months, respectively. After restriction to nulliparous couples, the proportions of couples 
1 who had not conceived and were still having unprotected intercourse at 6,12 and 24 months

2 after the start of the period of unprotected intercourse were $47 \%(95 \% \mathrm{Cl}, 26-68 \%), 26 \%$ (15-

$336 \%$ ) and $11 \%(7-16 \%)$, respectively (Figure IIB). In the analysis based on the alternative

4 fecundity measure (excluding from the initial population couples who had resorted to infertility

5 treatments, in order to estimate the proportion of couples who had not conceived nor started

6 infertility treatment and were still having unprotected intercourse), the rates at 6, 12 and 24

7 months after the start of the period of unprotected intercourse were $43 \%(95 \% \mathrm{Cl}, 34-53 \%)$,

$8 \quad 20 \%(95 \% \mathrm{Cl}, 16-25 \%)$ and $8 \%(95 \% \mathrm{Cl}, 6-10 \%)$, respectively (Figure IIA).

9

10 Sensitivity analyses

11 Assuming a duration of 6 months of post-partum infertility instead of 3 led to the exclusion of 129 couples but had no impact on our estimates. Twelve women declared not to have had menstrual cycles over the last 12 months before inclusion, and, again, excluding them had no impact either on our results. Excluding couples who declared that they were trying to become pregnant and that they were using contraception sporadically $(n=113)$ yielded very slightly increased rates of involuntary infertility $(47 \%, 26 \%$ and $12 \%$ at 6,12 and 24 months, respectively). Including these couples with a halved current duration decreased the rates of involuntary infertility to $37 \%(95 \% \mathrm{Cl}, 28-47 \%), 20 \%(15-25 \%)$ and $9 \%(7-11 \%)$ at 6,12 and 24 months, respectively. 
1

2

3

4

5

6

7

8

9

DISCUSSION

Comparison with former studies

To our knowledge, our study is one of the first to estimate the frequency of involuntary infertility in a nation wide representative population sample and not relying on a retrospective study design.

Several studies using other designs have provided descriptions of the couple fecundity (e.g. Bonde, et al., 1998, Jensen, et al., 2001, Joffe, 2000, Karmaus, et al., 1999, Muller, et al., 2006, Scheike, et al., 2008, Slama, et al., 2008). Most of these studies relied on retrospectively collected information in women or men asked to describe earlier pregnancy attempts, using either pregnancy-based (Jensen, et al., 2001, Joffe, et al., 2005, Scheike, et al., 2008) or historically prospective (Karmaus, et al., 1999, Slama, et al., 2008) designs (the former design is restricted to pregnancy attempts ending in a pregnancy, while the latter also includes those ending with no pregnancy). In a historically prospective study, 932 couples from Denmark, Germany, Poland, Italy and Spain described their periods of unprotected intercourse resulting or not in a pregnancy, provided they had started less than 5 years prior to the interview (Karmaus, et al., 1999). When the analysis was restricted to the first period of unprotected intercourse, $23 \%$ of women had not conceived within the first 12 months of attempt (varying from $33 \%$ in Poland down to $15 \%$ in South Italy); when the most recent time of unprotected intercourse was considered (including current attempts started not more than 5 years before interview), the proportion of women who had not conceived within 12 months of unprotected intercourse was $29 \%$ (Karmaus, et al., 1999). In a historically prospective study in two French rural areas conducted in 2000 that considered pregnancy attempts started between 1985 and 2000, Slama et al. (2008) reported a rate of 12-month involuntary infertility of $16 \%$. In a prospective study among Danish first pregnancy planners followed-up for six months, 256 couples out of 430 conceived (Bonde, et al., 1998), which, after taking into account censoring, corresponds to a 6-month involuntary infertility rate of $36 \%$. In another cohort of 221 women from America who volunteered in 1983-1985 as they were 
1 planning to stop using birth-control methods in order to become pregnant, the 6-month

2 cumulative pregnancy rate was $78 \%$ (Wilcox, et al., 1988). Retrospective studies relying only

3 on periods of unprotected intercourse (or pregnancy attempts) leading to a live birth (the so-

4 called "pregnancy-based" design) yield lower rates of 12-month involuntary infertility: in

5 England, Joffe (2000) reported that $10 \%$ of couples whose first pregnancy attempt leading to

6 a live birth started in 1991-93 had needed more than 12 months to conceive. In another

7 pregnancy-based study in 4 European cities among couples who delivered in 1996-98, the

8 corresponding rate for couples recruited in Paris was 9.9\% (Jensen, et al., 2001); it ranged from 5 to $11 \%$ among fertile couples recruited using a similar design in four French cities in 2002-2003 (Muller, et al., 2006). In the Enquête Nationale Périnatale, a national sample constituted of all women who delivered in all French maternity units in a given week in 2003 (Blondel, et al., 2006), time to pregnancy could be defined for 10,262 out of 14,482 live births, and the rates of 6,12 and 24-month infertility were $32 \%(95 \%, 31-33 \%), 18 \%(95 \%$ $\mathrm{Cl}, 17-19 \%)$ and $6 \%(95 \% \mathrm{Cl}, 5-6 \%)$, respectively (Slama, et al., (in press)). Although our confidence intervals were relatively broad $(19 \%$ to $30 \%$ for the estimated rate of 12 -month infertility), our estimate of the rate of 12-month involuntary infertility is somewhat higher than the pregnancy-based values reported in the Enquête Nationale Périnatale. This is coherent with what can expected from the facts that the latter study did not take couples remaining infertile or giving up the pregnancy attempt into account and that couples fecund enough to have many children are over-represented in such a pregnancy-based study.

\section{Study population}

Our study is based on a random sample from the general population. The estimated participation rate of eligible couples was $63 \%$, which offers potential for bias. Our population was weighted to limit such bias. This weighing approach, consisting in making our population more similar to the general population in terms of age and age at the end of studies, is expected to correct efficiently for selection bias to the extent that factors associated with participation and fecundity level are statistically linked with these sociodemographic 
1 variables. Unlike some previous studies on time to pregnancy using a pregnancy-based 2 design, inclusion was not conditioned on couples having eventually obtained a pregnancy.

3 We tried to identify all couples possibly at risk of pregnancy, without excluding sterile or

4 subfertile couples. We chose not to condition inclusion on couples being currently trying to

5 become pregnant, because subfertile couples who had started a pregnancy attempt in order

6 to become pregnant may consider themselves subfertile or sterile after several months on

7 involuntary infertility, and may and consequently declare that they are not trying anymore to become pregnant although they still have unprotected intercourse. We reported additional

9 results limited to couples who declared to have started the period of unprotected intercourse in order to become pregnant so as to describe the fecundity of pregnancy planners, which turned out to be very similar to that estimated without that exclusion.

Including parous women may induce bias or limit representativeness of the population sample because previous reproductive history may impact persistency in trying to become pregnant; this may also limit comparability with future studies because of possible temporal changes in desired family size; for this reason, we also reported results restricted to nulliparous women. These women had a very slightly higher rate of 12-month involuntary infertility, compared to the overall population also including parous women.

Assumptions made by our design

Fecundity studies have several potential limitations. These relate in particular to the fact that couples with unplanned or mistimed pregnancies usually have no defined duration of unprotected intercourse; to variability in the delay before pregnancy detection, in access to and use of contraception or in desired family size. These limitations however apply to most other types of fecundity studies, and have been discussed at length elsewhere (see e.g., Joffe, et al., 2005, Key, et al., 2009, Slama, et al., 2006, Weinberg, et al., 1994); we will here focus on sources of bias and assumptions specific to our study design. Our cross-sectional design implies that couples who have had unprotected intercourse for a long time have a higher probability of inclusion than couples with a shorter waiting time; however this length- 
1 biased sampling is taken into account in the statistical analysis, which provides an unbiased

2 estimate under certain assumptions (Keiding, et al., 2002, Weinberg and Gladen, 1986). A

3 limitation of the design is that it does not allow one to distinguish couples who conceive a pregnancy from those who abandon the pregnancy attempt, either because they split or

5 resume contraception before they conceive; that is, a period of involuntary infertility as 6 defined in our study corresponds to the time until pregnancy occurrence or end of 7 unprotected intercourse with no pregnancy. Data on the frequency of couples stopping a period of unprotected intercourse before pregnancy occurrence are limited; persistency in trying to become pregnant may vary according to mother's age at starting date, country (Basso, et al., 2000), and probably other factors such as parity. The impact of such attempts on the estimates from the current duration approach is expected to correspond to an overestimation of the fecundity level, whose amplitude will depend on the frequency of these attempts terminated because the couple split or resumed contraception. As forcefully pointed out by Basso et al. (Basso, et al., 2000), these pregnancy attempts not ending in a pregnancy also constitute a source of bias in the pregnancy-based design, which does not allow including them either and in which the collected time to pregnancy is conditioned on couples not giving up the period of unprotected intercourse; in that design also, their exclusion leads to an overestimation of the fecundity level. In a prevalent cohort based on couples recruited after less than 12 months of pregnancy attempt, the proportion of couples who reported to discontinue trying to become pregnant during the following year was $5 \%$ (Wise, et al., 2010). Compared to what had originally been suggested (Keiding, et al., 2002, Slama, et al., 2006), we report here results including couples who had initiated an infertility treatment since the start of the period of unprotected intercourse (as well as analyses excluding these couples, corresponding to the approach used in our previous publication). If these couples with infertility treatment are excluded, then the studied event is either pregnancy, or end of the period of unprotected intercourse or start of a fertility treatment; if these couples with infertility treatment are included, then the event is simply either pregnancy or end of the period of unprotected intercourse; both estimates are worth reporting. 
1 Coherently, including these couples yielded a somewhat higher frequency of 12-month 2 involuntary infertility (24\%, compared to $20 \%$ if couples with a treatment are excluded), 3 corresponding to a longer time to event.

4

5 Relevance of the current duration approach to describe fecundity

6 Describing and possibly monitoring couple fecundity takes on importance in the context of 7 increasing use of ART and of the possible deterioration of male reproductive health. Indeed, several studies have described temporal decreases in sperm concentration and motility in specific areas of industrialised countries over the last decades (Auger, et al., 1995, Carlsen, et al., 1992, Nelson and Bunge, 1974, Swan, et al., 2000). These decreases cannot be considered as certain, in particular because studies reporting temporal trends in semen quality are often based on self-selected subjects, not allowing quantification of participation rates and description of possible selection bias (Cohn, et al., 2002, Eustache, et al., 2004, Hauser, et al., 2005, Muller, et al., 2004). If true, such a decline might have had an impact on fecundability, the cycle-specific probability of pregnancy among non-contracepting couples, as indicated by a simulation study (Slama, et al., 2004). This decline in fecundability may not imply strong changes in the average number of children per couple, but could entail increases in the proportion of couples subject to 1 - to 5 -year involuntary infertility (Leridon and Slama, 2008).

Very few studies directly tried to assess temporal trends in fecundability or involuntary infertility of populations (Jensen, et al., 2005, Joffe, 2000, 2008). These studies generally do not cover areas where temporal declines in semen quality have been reported. Results do not show decreases in couple fecundity. Their pregnancy-based design excludes couples who remain involuntarily infertile, therefore limiting the statistical power of analyses trying to highlight changes in fecundity, and possibly biasing the comparison towards absence of change in fecundity (Slama, et al., 2004). Additionally, it has been argued that temporal trends in the proportion of unwanted pregnancies and abortion rates may make it difficult to describe time trends in fecundity (Sallmen, et al., 2005). Several approaches can be used to 
1 correct for these potential biases (Joffe, et al., 2006, Joffe, et al., 2005, Key, et al., 2009) but

2 the efficiency of these approaches may in practice be limited in the context of a retrospective

3 survey design (Sallmen, et al., 2006). For these reasons, alternatives to a retrospective

4 design are worth investigating. These include the (incident) cohort design (Bonde, et al.,

5 1998), the prevalent cohort design (Keiding, 1992, Wise, et al., 2010) and the current

6 duration approach. Other designs have been suggested (Olsen and Andersen, 1999) but not

7 applied to our knowledge.

8 The eligibility rate in the current duration approach is relatively low; we had to survey 15,810

9 couples in order to recruit 867 couples (5.5\%) with a defined current duration of unprotected

10 intercourse. This eligibility rate is higher than that of the main other prospective design, the

11 (classical) cohort design, in which couples are recruited before the start of the period of unprotected intercourse. Indeed, less than $2 \%$ of women aged 18-44 years contacted indicated that they planned to start a pregnancy attempt within the next 6 months, out of which probably not all will do so within this duration. Conversely, some couples may start a pregnancy attempt in the same time period without having planned it long in advance, and these would be hard to identify and include in an incident cohort. These study designs are actually not incompatible one with the other; indeed, couples who plan to start a pregnancy attempt soon (eligible in an incident or prevalent cohort on fecundity) can also be identified from the eligibility questionnaire of a current-duration study such as ours, and these can be followed-up, together with couples eligible for the current duration design at the time of interview. If repeated at regular time intervals, such a design could be used to prospectively monitor time trends in fecundity. This could be seen as a parallel to the studies monitoring semen quality in young men in Scandinavian countries (Jorgensen, et al., 2006); as suggested by Olsen and Rachootin (2003), a system monitoring fecundity should monitor semen quality in parallel to a measure of the couple fecundity such as involuntary infertility. In conclusion, our study provides an estimate of the frequency of involuntary infertility in the general population showing that about one in four to five couples have not conceived a 
1 detected pregnancy and are still having unprotected intercourse 12 month after having

2 stopped using a contraceptive method, and that about one couple out of ten may still be 3 unsuccessful in conceiving after 2 years of unprotected intercourse.

4 


\section{AUTHORS' ROLES}

$2 \mathrm{RS}$ and JB initiated the study. RS, BD, NK, AB and JB designed the study and 3 questionnaires; $A B, B D, J B$ and RS supervised data collection. $A B, B D$ and $R S$ cleaned and 4 prepared data. The statistical analyses were planned and supervised by RS and NK and 5 carried out by $\mathrm{OH}$, DS and LGA. RS drafted the first version of the manuscript. BD, LGA, 6 MJCE, LR, JCT, NK and JB critically reviewed the manuscript.

ACKNOWLEDGEMENTS

9 We thank Alfred Spira and Caroline Moreau for useful comments on the manuscript and 10 Lucette Aussel for her technical assistance in the step of data collection. We are grateful to 11 Henri Leridon for useful discussions and documentation.

FUNDING

The study was funded by grants from ANR (French Agency for Research, SEST call on 15 Environmental and Occupational Health), ANSES (French Agency for Food, environmental and Occupational Health Safety, EST call on Environmental and Occupational Health), InVS (French Institute for Public Health Surveillance). The team of Environmental Epidemiology is funded by an AVENIR grant from Inserm (2007). The funding sources had no role on the design of the study, with the exception of members of InVS who were implied in the development of some parts of the study questionnaire. 
1

2

3

4

5

6

7

8

9

10

\section{REFERENCES}

Auger J, Kunstmann JM, Czyglik F, Jouannet P. Decline in semen quality among fertile men in Paris during the past 20 years [see comments]. N Engl J Med 1995;332:281-285.

Basso O, Juul S, Olsen J. Time to pregnancy as a correlate of fecundity: differential persistence in trying to become pregnant as a source of bias. Int $J$ Epidemiol 2000;29:856-861.

Blondel B, Supernant K, Du Mazaubrun C, Breart G. [Trends in perinatal health in metropolitan France between 1995 and 2003: results from the National Perinatal Surveys]. J Gynecol Obstet Biol Reprod (Paris) 2006;35:373-387.

Bonde JP, Ernst E, Jensen TK, Hjollund NH, Kolstad H, Henriksen TB, Scheike T, Giwercman A, Olsen J, Skakkebaek NE. Relation between semen quality and fertility: a population-based study of 430 first-pregnancy planners. Lancet 1998;352:1172-1177.

Bonde JP, Hjollund NH, Jensen TK, Ernst E, Kolstad H, Henriksen TB, Giwercman A, Skakkebaek NE, Andersson AM, Olsen J. A follow-up study of environmental and biologic determinants of fertility among 430 Danish first-pregnancy planners: design and methods. Reprod Toxicol 1998;12:19-27.

Buck GM, Lynch CD, Stanford JB, Sweeney AM, Schieve LA, Rockett JC, Selevan SG, Schrader SM. Prospective pregnancy study designs for assessing reproductive and developmental toxicants. Environ Health Perspect 2004;112:79-86.

Carlsen E, Giwercman A, Keiding N, Skakkebaek NE. Evidence for decreasing quality of semen during past 50 years. British Medical Journal 1992;305:609-613.

Cohn BA, Overstreet JW, Fogel RJ, Brazil CK, Baird DD, Cirillo PM. Epidemiologic studies of human semen quality: considerations for study design. Am J Epidemiol 2002;155:664671.

de Mouzon J, Lancaster P, Nygren KG, Sullivan E, Zegers-Hochschild F, Mansour R, Ishihara O, Adamson D. World collaborative report on Assisted Reproductive Technology, 2002. Human reproduction 2009;24:2310-2320. 
1 de Mouzon J, Goossens V, Bhattacharya S, Castilla JA, Ferraretti AP, Korsak V, Kupka M,

Nygren KG, Nyboe Andersen A. Assisted reproductive technology in Europe, 2006: results generated from European registers by ESHRE. Human reproduction 2010;25:1851-1862.

Deville JC, Särndal CE, Sautory O. Generalized raking procedures in survey sampling. Journal of the American Statistical Association 1993;88:1013-1020.

Eustache F, Auger J, Cabrol D, Jouannet P. Are volunteers delivering semen samples in fertility studies a biased population? Hum Reprod 2004;19:2831-2837.

Guzick DS, Swan S. The decline of infertility: apparent or real? Fertil Steril 2006;86:524-526; discussion 534.

Hauser R, Godfrey-Bailey L, Chen Z. Does the potential for selection bias in semen quality studies depend on study design? Experience from a study conducted within an infertility clinic. Hum Reprod 2005;20:2579-2583.

INSEE SAS macro CALMAR. INSEE (National Institute of Statistics and Economic Studies http://www.insee.fr/fr/methodes/default.asp?page=outils/calmar/accueil calmar.htm (accessed 30 March 2011).

Jensen TK, Slama R, Ducot B, Suominen J, Cawood E, Andersen AG, Eustache F, Irvine S, Auger J, Jouannet $\mathrm{P}$ et al. Regional differences in waiting time to pregnancy among couples from four European cities. Human Reproduction 2001;16:2697-2704.

Jensen TK, Joffe M, Scheike T, Skytthe A, Gaist D, Christensen K. Time trends in waiting time to pregnancy among Danish twins. Hum Reprod 2005;20:955-964.

Joffe M. Time trends in biological fertility in Britain [see comments]. Lancet 2000;355:19611965.

Joffe M, Key J, Best N, Keiding N, Scheike T, Jensen TK. Studying time to pregnancy by use of a retrospective design. Am J Epidemiol 2005;162:115-124.

Joffe M, Key J, Best N, Keiding N, Jensen TK. Human fertility decline? Epidemiology 2006;17:238; author reply 238-239. 
1 Joffe M, Key J, Best N, Jensen TK, Keiding N. The role of biological fertility in predicting family size. Human reproduction 2009;24:1999-2006.

Jorgensen N, Asklund C, Carlsen E, Skakkebaek NE. Coordinated European investigations of semen quality: results from studies of Scandinavian young men is a matter of concern. Int J Androl 2006;29:54-61; discussion 105-108.

Juul S, Karmaus W, Olsen J. Regional differences in waiting time to pregnancy: pregnancybased surveys from Denmark, France, Germany, Italy and Sweden. The European Infertility and Subfecundity Study Group. Hum Reprod 1999;14:1250-1254.

Karmaus W, Juul S, on behalf of the European infertility and subfecundity study group. Infertility and subfecundity in population-based samples from Denmark, Germany, Poland and Spain. European Journal of Public Health 1999;9:229-235.

Keiding N. Independent delayed entry (with discussion). In Klein, J. P. and Goel, P. K. (eds) Survival analysis: State of the Art. 1992. Kluwer, Dordrecht, pp.309-326.

Keiding N, Kvist K, Hartvig H, Tvede M, Juul S. Estimating time to pregnancy from current durations in a cross-sectional sample. Biostatistics 2002;3:565-578.

Key J, Best N, Joffe M, Jensen TK, Keiding N. Methodological issues in analyzing time trends in biologic fertility: protection bias. American journal of epidemiology 2009;169:285-293.

Larsen U, Vaupel JW. Hutterite fecundability by age and parity: strategies for frailty modeling of event histories. Demography 1993;30:81-102.

Leridon $\mathrm{H}$. Sterility and Subfecundity: from silence to impatience. Population: an English selection 1992;4:35-54.

Leridon $\mathrm{H}$. Studies of fertility and fecundity: comparative approaches from demography and epidemiology. C R Biol 2007;330:339-346.

Leridon $\mathrm{H}$, Slama $\mathrm{R}$. The impact of a decline in fecundity and of pregnancy postponement on final number of children and demand for assisted reproduction technology. Hum Reprod 2008;23:1312-1319. 
1 Moreau C, Ducot B, Spira A, Slama R. When do infertile couples choose to seek medical help? Fertil Steril 2010;93:737-744.

Muller A, De La Rochebrochard E, Labbe-Decleves C, Jouannet P, Bujan L, Mieusset R, Le Lannou D, Guerin JF, Benchaib M, Slama R et al. Selection bias in semen studies due to self-selection of volunteers. Hum Reprod 2004;19:2838-2844.

Muller A, Slama R, Labbe-Decleves C, Jouannet P, Bujan L, Mieusset R, Le Lannou D, Guerin JF, Benchaib M, Spira A. Geographic variations in probability of pregnancy in four cities of France. Rev Epidemiol Sante Publique 2006;54:55-60.

Nelson CM, Bunge RG. Semen analysis: evidence for changing parameters of male fertility potential. Fertil Steril 1974;25:503-507.

Olsen J, Andersen PK. We should monitor human fecundity, but how? A suggestion for a new method that may also be used to identify determinants of low fecundity. Epidemiology 1999;10:419-421.

Olsen J, Rachootin P. Invited Commentary: Monitoring Fecundity over Time-If We Do It, Then Let's Do It Right. Am J Epidemiol 2003;157:94-97.

Sallmen M, Lindbohm ML, Nurminen M. Paternal exposure to lead and infertility. Epidemiology 2000;11:148-152.

Sallmen M, Weinberg CR, Baird DD, Lindbohm ML, Wilcox AJ. Has Human Fertility Declined Over Time?: Why We May Never Know. Epidemiology 2005;16:494-499.

Sallmen M, Baird DD, Wilcox A, Weinberg CR, Lindbohm ML. Human Fertility Decline? (Author reply). Epidemiology 2006;17:238-239.

Scheike TH, Rylander L, Carstensen L, Keiding N, Jensen TK, Stromberg U, Joffe M, Akre O. Time trends in human fecundability in Sweden. Epidemiology 2008;19:191-196.

Slama R, Kold-Jensen T, Scheike T, Ducot B, Spira A, Keiding N. How would a decline in sperm concentration over time influence the probability of pregnancy? Epidemiology 2004;15:458-465. 
1 Slama R, Ducot B, Carstensen L, Lorente C, de La Rochebrochard E, Leridon H, Keiding N, Bouyer J. Feasibility of the Current-Duration Approach to Studying Human Fecundity. Epidemiology 2006;17:440-449.

Slama R, Boutou O, Ducot B, Spira A. Reproductive life events in the population living in the vicinity of a nuclear waste reprocessing plant. $J$ Epidemiol Community Health 2008;62:513-521.

Slama R, Ducot B, Keiding N, Blondel B, Bouyer J. (Fecundity of couples in France). Bulletin d'Epidémiologie Hebdomadaire (in press).

Stephen EH, Chandra A. Declining estimates of infertility in the United States: 1982-2002. Fertil Steril 2006;86:516-523.

Swan SH, Elkin EP, Fenster L. The Question of Declining Sperm Density Revisited: An Analysis of 101 Studies Published 1934-1996. Environ Health Perspect 2000;108:961966.

Tietze C. Fertility after discontinuation of intrauterine and oral contraception. Int $J$ Fertil 1968;13:385-389.

van Es B, Klaassen CAJ, Oudshoorn K. Survival analysis under cross-sectional sampling: length bias and multiplicative censoring. J Stat Plan Infer 2000;91:295-312.

Weinberg CR, Gladen BC. The beta-geometric distribution applied to comparative fecundability studies. Biometrics 1986;42:547-560.

Weinberg CR, Baird DD, Wilcox AJ. Sources of bias in studies of time to pregnancy. Stat Med 1994;13:671-681.

Wilcox AJ, Weinberg CR, O'Connor JF, Baird DD, Schlatterer JP, Canfield RE, Armstrong EG, Nisula BC. Incidence of early loss of pregnancy. N Engl J Med 1988;319:189-194.

Wise LA, Rothman KJ, Mikkelsen EM, Sorensen HT, Riis A, Hatch EE. An internet-based prospective study of body size and time-to-pregnancy. Human reproduction 2010;25:253-264.

Yamaguchi K. Accelerated failure-time mover-stayer regression models for the analysis of last-episode data. Sociological Methodology 2003;33:81-110. 
1 Zinaman MJ, Brown CC, Selevan SG, Clegg ED. Semen quality and human fertility: a 2 prospective study with healthy couples. J Androl 2000;21:145-153.

3

4 
2 Table I: Characteristics of the women who replied to the eligibility questionnaire.

\begin{tabular}{|c|c|c|c|c|c|c|}
\hline \multirow{3}{*}{ Characteristic } & \multicolumn{2}{|c|}{ Whole population $(n=15,810)$} & \multicolumn{4}{|c|}{ Current duration group } \\
\hline & \multirow[t]{2}{*}{$\mathrm{n}$} & \multirow[t]{2}{*}{ Weighted $\%^{\mathrm{a}}$} & \multicolumn{2}{|c|}{ Yes $(n=867)$} & \multicolumn{2}{|c|}{ No $(n=14,943)$} \\
\hline & & & $\mathrm{n}$ & Weighted $\%^{a}$ & $\mathrm{n}$ & $\%^{a}$ \\
\hline \multicolumn{7}{|l|}{ Age at interview (years) } \\
\hline $18-24$ & 2,756 & 22.8 & 53 & 9.4 & 2,703 & 23.5 \\
\hline $25-29$ & 2,601 & 17.1 & 193 & 25.0 & 2,408 & 16.7 \\
\hline $30-34$ & 3,048 & 19.2 & 254 & 30.4 & 2,794 & 18.6 \\
\hline $35-39$ & 3,836 & 20.5 & 222 & 21.0 & 3,614 & 20.4 \\
\hline $40-44$ & 3,569 & 20.5 & 145 & 14.2 & 3,424 & 20.8 \\
\hline \multicolumn{7}{|l|}{ Currently has a male partner } \\
\hline Yes & 12,178 & 66.9 & 867 & 100 & 11,311 & 65.1 \\
\hline No & 3,632 & 33.1 & 0 & 0 & 3,632 & 34.9 \\
\hline \multicolumn{7}{|l|}{ Number of children } \\
\hline 0 & 5,420 & 38.7 & 360 & 42.3 & 5,060 & 38.5 \\
\hline 1 & 3,016 & 20.4 & 281 & 32.9 & 2,735 & 19.7 \\
\hline 2 & 4,693 & 24.8 & 159 & 15.2 & 4,534 & 25.3 \\
\hline 3 and more & 2,681 & 16.2 & 67 & 9.6 & 2,614 & 16.5 \\
\hline \multicolumn{7}{|l|}{ Current contraception } \\
\hline Yes, systematically used & 13,105 & 82.0 & 0 & 0 & 13,105 & 86.5 \\
\hline Yes, sporadically used & 136 & 0.9 & 113 & 13.1 & 23 & 0.2 \\
\hline No method to avoid pregnancy ${ }^{\mathrm{b}}$ & 2,150 & 14.3 & 754 & 86.9 & 1,396 & 10.4 \\
\hline Surgical sterilisation ${ }^{c}$ & 406 & 2.8 & 0 & 0 & 406 & 2.9 \\
\hline Do not know & 13 & 0.1 & 0 & 0 & 13 & 0.1 \\
\hline \multicolumn{7}{|l|}{ Defined CDUI } \\
\hline Yes & 867 & 5.2 & 867 & 100 & 0 & 0 \\
\hline No & 14,943 & 94.9 & 0 & 0 & 14,943 & 100 \\
\hline \multicolumn{7}{|l|}{ Planning to try to become pregnant ${ }^{a}$} \\
\hline Yes, currently trying & 859 & 5.5 & 655 & 75.6 & 204 & 1.5 \\
\hline Yes, will start within 1 or 2 months & 27 & 0.1 & 3 & 0.3 & 24 & 0.1 \\
\hline Yes, in about 3 months & 60 & 0.4 & 2 & 0.1 & 58 & 0.4 \\
\hline Yes, within 4-6 months & 181 & 0.9 & 1 & 0.03 & 180 & 1.0 \\
\hline Yes, within 7-12 months & 511 & 3.0 & 12 & 1.7 & 499 & 3.1 \\
\hline Yes, in more than a year & 1,789 & 12.0 & 17 & 2.2 & 1,772 & 12.5 \\
\hline Yes, but not planned when & 3,460 & 24.9 & 32 & 4.0 & 3,428 & 26.1 \\
\hline No & 7,700 & 48.1 & 139 & 15.6 & 7,561 & 49.9 \\
\hline Does not know & 57 & 0.4 & 6 & 0.5 & 51 & 0.4 \\
\hline Currently pregnant & 751 & 4.8 & 0 & 0 & 751 & 5.0 \\
\hline
\end{tabular}

\footnotetext{
3 CDUI: Current duration of unprotected intercourse.

${ }^{a}$ Percentages were corrected for possible selection bias and over-representation of urban compared to rural areas.

${ }^{\mathrm{b}}$ Including pregnant women.

${ }^{c}$ Surgical sterilisation corresponded to tubal ligation, vasectomy or hysterectomy.

${ }^{\mathrm{d}}$ Women with surgical sterilisation have not been asked about pregnancy planning.
}

10

11 
1 Table II: Characteristics of the 867 women with defined current duration of unprotected

2 intercourse.

\begin{tabular}{|c|c|c|}
\hline Characteristic & $\mathrm{n}$ & Weighted $\%^{\mathrm{a}}$ \\
\hline \multicolumn{3}{|l|}{ Age at interview } \\
\hline $18-24$ years & 53 & 9.4 \\
\hline $25-29$ years & 193 & 24.9 \\
\hline $30-34$ years & 254 & 30.4 \\
\hline $35-39$ years & 222 & 21.0 \\
\hline $40-44$ years & 145 & 14.2 \\
\hline \multicolumn{3}{|c|}{ Age at start of period of unprotected intercourse } \\
\hline $18-24$ years & 101 & 16.2 \\
\hline $25-29$ years & 263 & 32.7 \\
\hline 30-34 years & 293 & 30.1 \\
\hline $35-39$ years & 175 & 17.6 \\
\hline $40-44$ years & 35 & 3.3 \\
\hline \multicolumn{3}{|l|}{ Number of children } \\
\hline 0 & 360 & 42.3 \\
\hline 1 & 281 & 32.9 \\
\hline 2 & 159 & 15.2 \\
\hline 3 and more & 67 & 9.6 \\
\hline \multicolumn{3}{|c|}{ Frequency of sexual intercourse } \\
\hline $1-3$ per month & 165 & 18.0 \\
\hline 1-2 per week & 418 & 47.5 \\
\hline >2 per week & 269 & 34.6 \\
\hline \multicolumn{3}{|c|}{ Duration of menstrual cycle } \\
\hline$<27$ days & 161 & 24.2 \\
\hline $27-29$ days & 356 & 42.4 \\
\hline$>29$ days & 273 & 33.5 \\
\hline \multicolumn{3}{|c|}{ Medical treatment for infertility since start of the PUI } \\
\hline No & 708 & 83.4 \\
\hline Yes & 159 & 16.6 \\
\hline \multicolumn{3}{|c|}{ Started the PUI to obtain a pregnancy } \\
\hline Yes & 708 & 80.8 \\
\hline No & 159 & 19.3 \\
\hline \multicolumn{3}{|c|}{ Currently trying to become pregnant } \\
\hline Yes & 655 & 75.6 \\
\hline No & 212 & 24.4 \\
\hline \multicolumn{3}{|c|}{ Smoking at the start of the PUI } \\
\hline No & 580 & 62.0 \\
\hline Yes & 279 & 38.0 \\
\hline \multicolumn{3}{|c|}{ Body mass index $\left(\mathrm{kg} / \mathrm{m}^{2}\right)$} \\
\hline$<18.5$ & 78 & 10.9 \\
\hline $18.5-19.9$ & 132 & 12.9 \\
\hline $20-22.4$ & 248 & 25.4 \\
\hline $22.5-24.9$ & 163 & 20.0 \\
\hline $25-29.9$ & 151 & 18.8 \\
\hline$\geq 30$ & 82 & 12.0 \\
\hline \multicolumn{3}{|c|}{ Current duration of unprotected intercourse ${ }^{b}$} \\
\hline$<3$ months & 182 & 20.2 \\
\hline 3-5.9 months & 113 & 12.9 \\
\hline 6-11.9 months & 118 & 13.2 \\
\hline $12-23.9$ months & 130 & 16.2 \\
\hline 24-35.9 months & 75 & 8.9 \\
\hline$\geq 36$ months & 249 & 28.6 \\
\hline
\end{tabular}

PUI: Period of Unprotected Intercourse

${ }^{a}$ Percentages were corrected for possible selection bias and over-representation of urban compared to rural areas by a reweighting approach. This explains why the variables relative to medical treatment and to whether couples started the PUI to obtain a pregnancy have different weighted percentages although the number of subjects in each "Yes" and "No" categories, and hence the unweighted percentages, are the same.

$\mathrm{b}$ The distribution of the current duration of unprotected intercourse declared by couples has no direct interpretation due to the length-biased sampling and should therefore not be interpreted as an estimate of the frequency of involuntary infertility (given in Figure II). 
1

2

3 Figure I: Flow chart of study population.

4

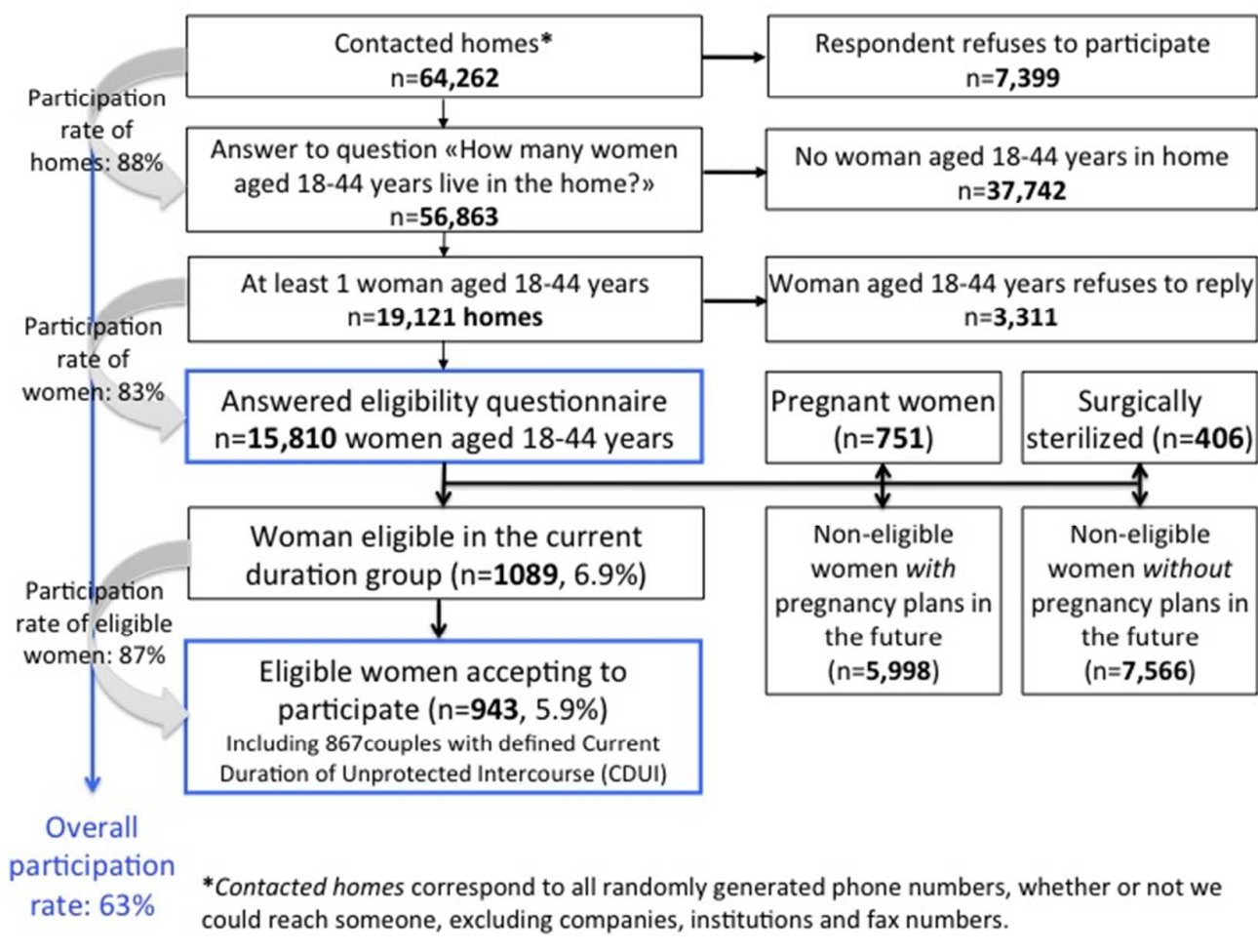


Figure II: Estimation of the proportion of sexually active couples still without detected pregnancy and still not using contraception, as a function of the number of months elapsed since the start of the period of unprotected intercourse. The usual clinical definitions of infertility would correspond to the values at 12 and 24 months. A) Whole eligible population ( $n=867$, and $n=708$ after restriction to non treated couples); B) nulliparous couples only ( $n=360$ and $n=277$ after restriction to non treated couples).

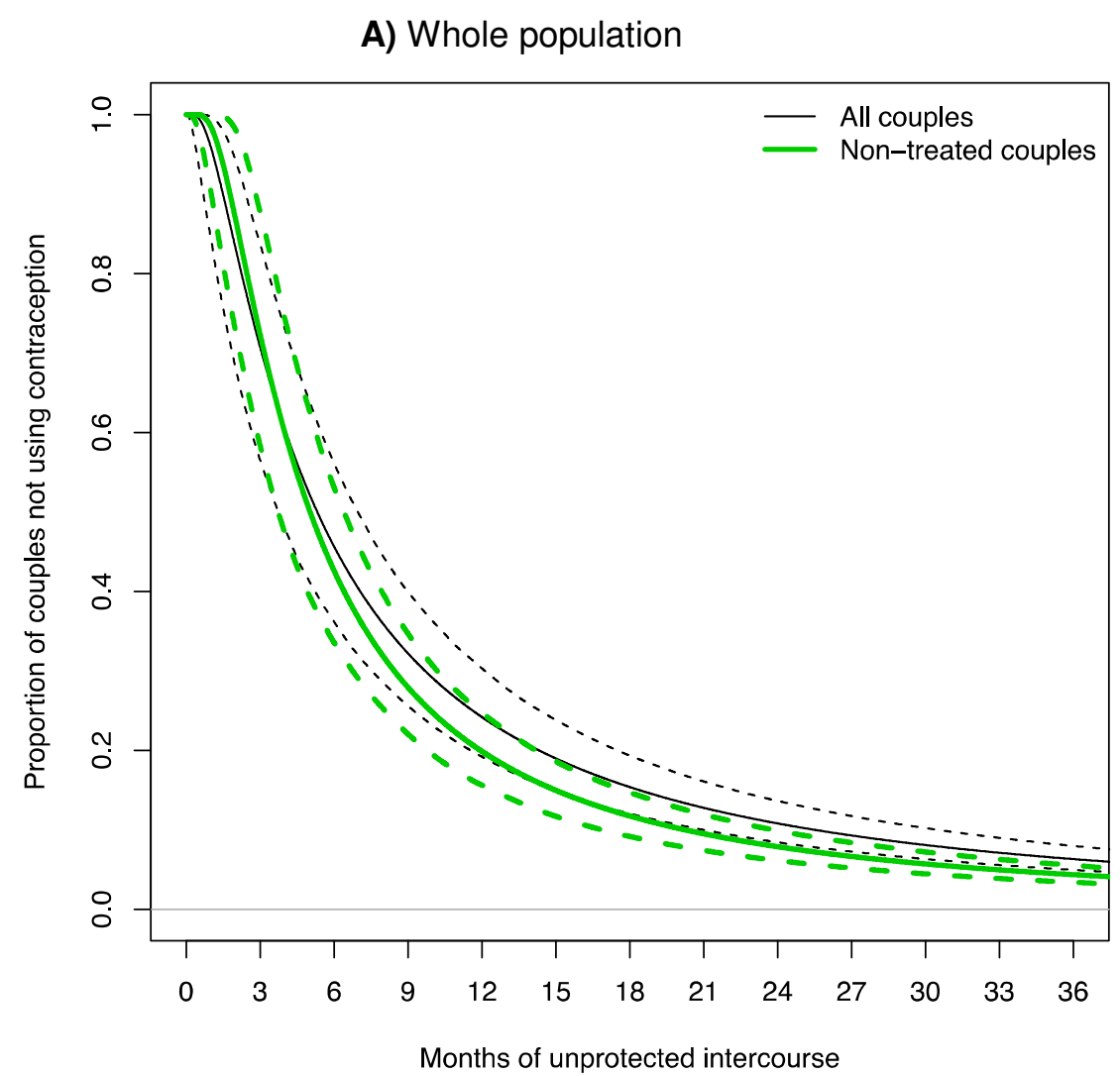

B) Nulliparous couples

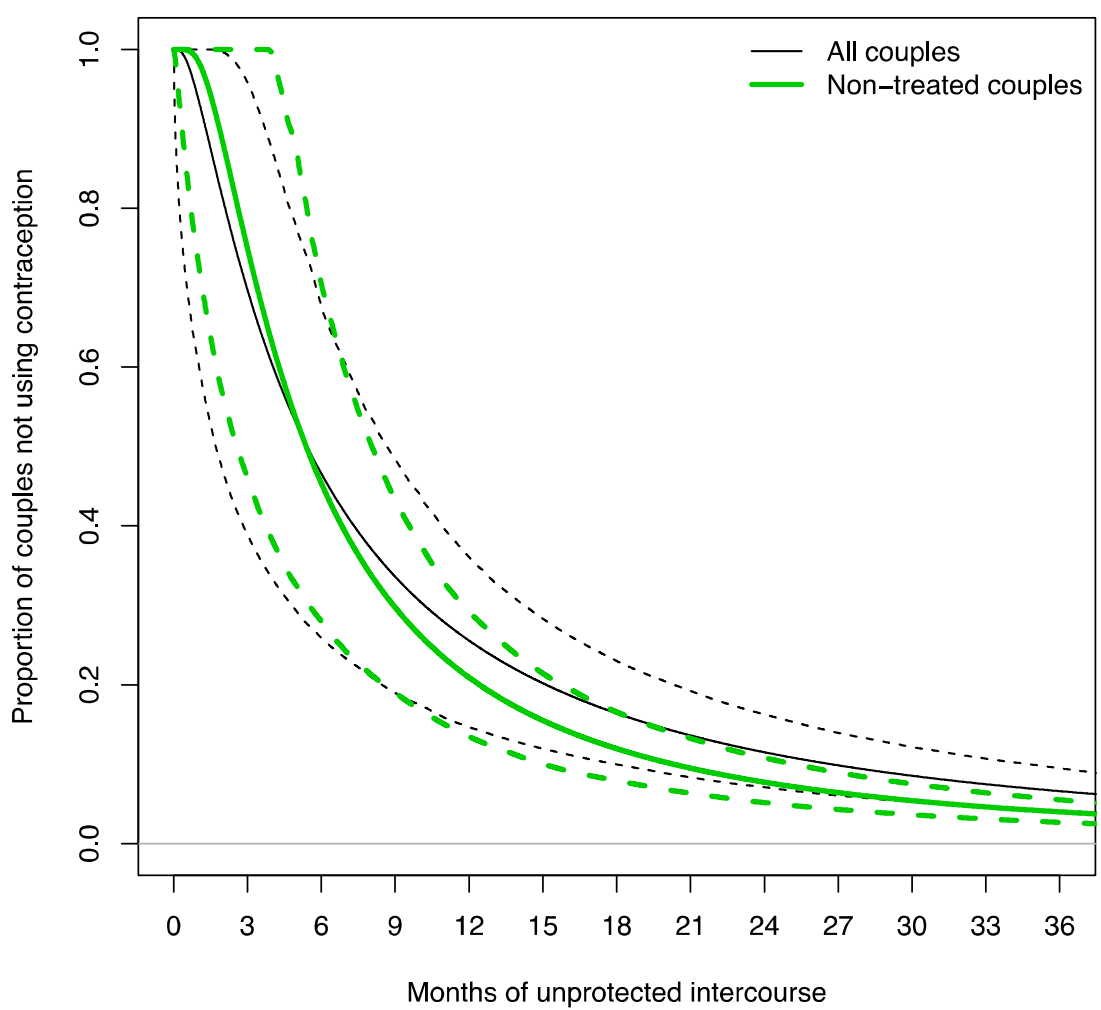

The survival function corresponding to time until pregnancy or end of the period of unprotected intercourse without pregnancy is indicated by the black solid line (estimated from the whole population at risk of pregnancy at inclusion). The green curve is the same estimate, but recomputed after exclusion of couples who had begun treatment for infertility. Dotted curves indicate $95 \%$ confidence intervals. 